\title{
Serum Levels of Soluble Fms like Tyrosine Kinase-1(sFlt-1) in Normotensive and Preeclamptic Pregnancy
}

\author{
Yadav $\mathbf{S}^{1}$, Singh $\mathrm{Y}^{2}$, Natu $\mathrm{SM}^{3}$, Goel MM+, Singh $\mathrm{U}^{5}$, Tondon $\mathrm{P}^{6}$ \\ Sonali Yadav ${ }^{1}$ Ph.D, Yogendra Singh M.D², S.M.Natu ${ }^{1}$ Ph.D, M.M. Goel ${ }^{1}$ M.D, Urmila Singh ${ }^{3}$ M.D, Pushpa Tondon ${ }^{1}$ Ph.D. \\ Department of Pathology ${ }^{1}$, Department of Medicine ${ }^{2}$, Department of Obstetrics and Gynecology ${ }^{3}$ King George's Medical \\ University, Lucknow, Uttar Pradesh, India.
}

Address for correspondence: Sonali Yadav, E-mail: sonalikgmu@gmail.com

\begin{abstract}
Background: The study aimed to measure serum levels of sFlt-1 throughout pregnancy in normotensive and preeclamptic women and to determine if sFlt-1 concentrations alter before the clinical manifestation of the condition. Material and Methods: It was a nested case control study. Serum samples were collected during pregnancy at three different gestational periods (12-20 weeks, 21-28 weeks and 29- till term) and one sample post delivery, from within the cohort of pregnant women reporting to antenatal clinic. The subjects were divided in to normotensive (controls) and preeclamptic (cases) groups. Circulating levels of antiangiogenic (sFlt-1) were analyzed by enzyme linked immunosorbent assay (ELISA). Results: Maternal serum concentrations of sFlt-1 increased with the advancement of gestation age in both normotensive and preeclamptic pregnancies but significantly more increased levels were observed in preeclamptic pregnancies as compared with normotensive pregnancies. Conclusion: Maternal circulating sFlt-1 concentrations were significantly higher in women with preeclampsia, which may contribute to the development of preeclampsia.
\end{abstract}

Keywords: Pregnancy, Preeclampsia, Soluble Fms like Tyrosine Kinase-1.

\section{Introduction}

Preeclampsia, a life-threatening pregnancy specific syndrome, characterized by pregnancy induced hypertension $(\mathrm{BP} \geq 140 / 90 \mathrm{~mm} \mathrm{Hg}$ ) and proteinuria of 300 $\mathrm{mg} / 24$ hour or more after 20 weeks of gestation ${ }^{1}$. Preeclampsia is a medical disorder during pregnancy that could lead to high risk of fetal growth retardation, premature delivery and even maternal death ${ }^{2,3}$. Alternative splicing of the VEGF receptor Flt-1 results in the production of an endogenously secreted antiangiogenic

Manuscript received: $06^{\text {th }}$ Aug 2013

Reviewed: $13^{\text {th }}$ Aug 2013

Author Corrected: $19^{\text {th }}$ Aug 2013

Accepted for Publication: $27^{\text {th }}$ Aug 2013 protein referred to as sFlt1, which lacks the transmembrane and cytoplasmic domain of the membrane-bound receptor

${ }^{4}$. Thus sFlt1 can antagonize vascular endothelial growth factor (VEGF) and placental growth factor (PLGF) by binding to them and preventing interaction with their endogenous full-length receptors ${ }^{5}$. There is substantial evidence that increased production of sFlt-1 plays a major pathogenic role in the severe

endothelial dysfunction of preeclampsia. However, more recent studies have shown that circulating sFlt-1 is increased in the amniotic fluid in preeclampsia and in serum at the onset of preeclampsia in late gestation ${ }^{6,7}$. 
Although the primary trigger for abnormal placental development and excess sFlt1 production in preeclampsia remains speculative, our work suggests that excess sFlt1 may be sufficient to produce generalized endothelial dysfunction and some of the clinical phenotype noted in preeclampsia.The present study therefore was undertaken to estimate the maternal serum sFlt-1 concentrations throughout pregnancy among the women who subsequently developed preeclampsia, compared with their concentrations in normotensive pregnant women.

\section{Materials and Methods}

Study design \& setting: This was a tertiary care teaching hospital based nested case control study. Participants: With the approval of the institutional ethics committee and a written informed consent from each woman, a total of 105 healthy women with singleton pregnancy of 12-20 weeks of gestation were included in this study.

The gestational age of women, at the time of collection was determined by ultrasonographic examination. The women with history of essential hypertension, renal disease, epilepsy, diabetes or any other chronic or preexisting disease were excluded from the study. Peripheral blood samples were collected from recruited subjects at four time periods; first at 12-20 weeks (weeks), second at 21-28 weeks and third sample at 29 weeks of gestation to till term. The fourth blood sample i.e. the end point samples were obtained at 48 hours post delivery. Serum was separated and stored in multiple aliquots at $-80^{\circ} \mathrm{c}$ for estimation of sFlt-1. The sample collections were done from all women blinded to their preeclamptic or normotensive status. Out of 105 women registered, only 15 women developed preeclampsia. The criteria for diagnosis of preeclampsia were elevation of blood pressure $\geq 140 / 90 \mathrm{~mm} \mathrm{Hg}$ (measured at least 24 hours apart) and proteinuria of $\geq 300$ $\mathrm{mg} / 24$ hour or more after 20 weeks gestation.

Since the number of cases was significantly less than the number of controls therefore for each woman with preeclampsia, one normotensive control was selected from the cohort and matched according to gestational age.

\section{Estimation of sFlt1 by serum ELISA:}

Estimation of sFlt1 was determined by a commercially available enzyme linked immunosorbent assay (ELISA) kit, as per manufacturer's instructions, for sFlt1 (eBioscience, USA). Samples were run in duplicate. The minimal detection limit of assay for sFlt1 was $<30 \mathrm{pg} / \mathrm{ml}$.

\section{Statistical analysis}

Data were summarized as Mean \pm SE. Groups were compared by repeated measures two factor (Periods $\mathrm{x}$ Groups) analysis of variance (ANOVA) using general linear models (GLM) and the significance of mean difference within and between the groups was done by Newman-Keuls post hoc test. A two-sided $(\alpha=2) \mathrm{p}<0.05$ was considered statistically significant.

\section{Results}

Table 1: Demographic and clinical characteristics (mean \pm SE) of two groups

\begin{tabular}{|l|c|c|c|}
\hline \multicolumn{1}{|c|}{ Characteristic } & Controls $(\mathbf{n = 1 5})$ & Cases (n=15) & p value \\
\hline Age (year) & $25.66 \pm 1.01$ & $25.80 \pm 1.07$ & 0.929 \\
\hline Weight $(\mathrm{kg})$ & $54.46 \pm 2.40$ & $54.93 \pm 1.85$ & 0.879 \\
\hline Height $(\mathrm{cm})$ & $148.46 \pm 1.23$ & $146.46 \pm 1.04$ & 0.226 \\
\hline BMI $\left(\mathrm{kg} / \mathrm{m}^{2}\right)$ & $24.75 \pm 1.16$ & $25.65 \pm 0.90$ & 0.54 \\
\hline SBP $(\mathrm{mm} \mathrm{Hg})$ at 1st visit & $116.93 \pm 1.20$ & $718.93 \pm 1.82$ & 0.369 \\
\hline DBP $(\mathrm{mm} \mathrm{Hg})$ at 1st visit & $69.33 \pm 0.74$ & $36.80 \pm 0.35$ & 0.352 \\
\hline GA at delivery (weeks) & $39.00 \pm 0.25$ & $2.66 \pm 0.12$ & 0.000 \\
\hline Infant's birth weight (kg) & $3.01 \pm 0.08$ & $70.26 \pm 0.64$ & 0.028 \\
\hline
\end{tabular}


The demographic and clinical characteristics of two groups are summarized in Table 1. At presentation, the demographic characteristics viz. age, weight, height, BMI, SBP and DBP were similar $(\mathrm{p}>0.05)$ between the two groups i.e. not differed statistically.

However, clinical characteristics gestational age (GA) at delivery lowered significantly $(\mathrm{p}<0.001)$ in cases as compared to controls. Further, infant's birth weight was also significantly $(\mathrm{p}<0.001)$ lower in cases as compared to controls.

Table 2: sFlt1 levels (Mean $\pm \mathrm{SE}, \mathrm{n}=15)$ of two groups during gestational age

\begin{tabular}{|c|c|c|c|c|}
\hline \multirow{2}{*}{ Groups } & \multicolumn{3}{|c|}{ Gestational age } \\
\cline { 2 - 5 } & $\mathbf{1 2 - 2 0}$ weeks & 21-28 weeks & 29-till term & Post delivery \\
\hline Control & $281.67 \pm 22.77$ & $417.00 \pm 44.39^{a}$ & $1372.33 \pm 93.80^{\text {ab }}$ & $274.73 \pm 30.86^{b \mathbf{c}}$ \\
\hline Cases & ${ }^{\mathbf{n s}} 298.47 \pm 33.15$ & ${ }^{\mathbf{n s}} 511.46 \pm 61.03^{\text {a }}$ & ${ }^{* * *} 6929.73 \pm 1005.27^{\text {ab }}$ & ${ }^{\text {ns }} 324.20 \pm 45.32^{\text {bc }}$ \\
\hline
\end{tabular}

\section{Between groups:}

${ }^{\mathrm{ns}} \mathrm{p}>0.05$ or ${ }^{*} \mathrm{p}<0.05$ or ${ }^{* *} \mathrm{p}<0.01$ or ${ }^{* * *} \mathrm{p}<0.001-$ Control vs. Cases

\section{Within groups:}

${ }^{a} \mathrm{p}<0.05$ or ${ }^{\mathrm{a}} \mathrm{p}<0.01$ or ${ }^{\mathrm{a}} \mathrm{p}<0.001$ - as compared to $12-20$ weeks

${ }^{b} \mathrm{p}<0.05$ or ${ }^{\mathrm{b}} \mathrm{p}<0.01$ or ${ }^{\mathbf{b}} \mathrm{p}<0.001$ - as compared to $21-28$ weeks

${ }^{c} \mathrm{p}<0.05$ or ${ }^{\mathrm{c}} \mathrm{p}<0.01$ or ${ }^{\mathrm{c}} \mathrm{p}<0.001$ - as compared to 29 -till term

The sFlt-1 levels of two groups over the periods are summarized in Table 2 also shown graphically in Fig. 1. The mean sFlt- 1 levels in both groups increases up to 29- till term and thereafter decreases comparatively at post delivery.

Further, at all periods, the level of it was higher in cases than controls. Comparing the mean sFlt-1 levels within the groups (i.e. between

periods), the sFlt-1 levels in both groups were significantly $(\mathrm{p}<0.001)$ higher at 21-28 weeks and 29- till term as compared to 12-20 weeks.

Further, in both groups, the level of it was also significantly $(\mathrm{p}<0.001)$ higher at 29-term as compared to 21-28 weeks. However, in both the groups, it lowered at post delivery as compared to other periods.

Similarly, comparing the mean sFlt-1 levels between the groups, the sFlt-1 levels differed significantly $(\mathrm{p}<0.001)$ at 29 till term, but did not differed significantly $(\mathrm{p}>0.05)$ at 12-20 weeks and 21-28 weeks between the two groups. 


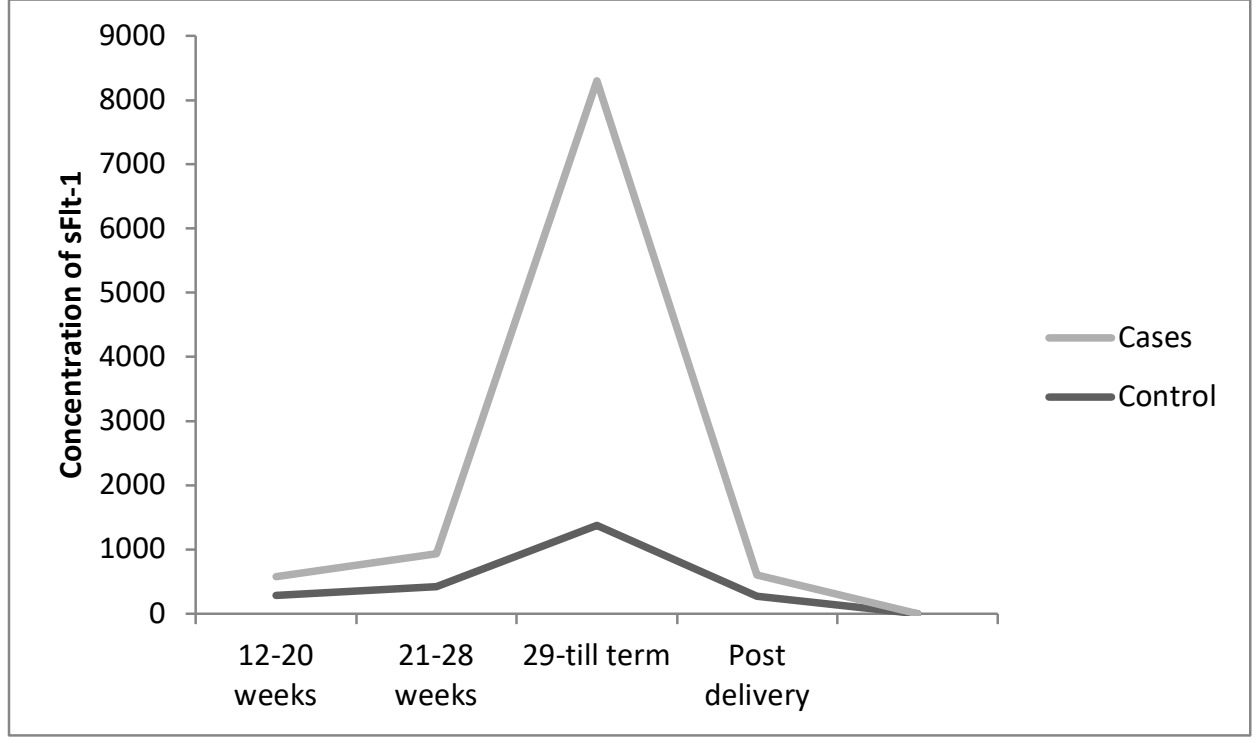

Fig 1: The sFlt-1 levels of two groups over the periods (Pregnancy up to delivery)

\section{Discussion}

Role of imbalance of angiogenic factors in the genesis of preeclampsia has been proposed by several investigators ${ }^{8}$, 9, 10,11. Maynard et al. (2003), in their experimental model have shown development of preeclampsia like phenotype in pregnant rats, when induced with high circulating sFlt, suggesting that the antiangiogenic factor sFlt might have a pathogenic role in preeclampsia ${ }^{9}$.

In the present study we evaluated the levels of sFlt-1 with the progression of gestational age in both normotensive and preeclamptic women. We observed that the levels of sFlt1 were increased in both normotensive (controls) and preeclamptic women (cases) with the progression of gestational age and decreased thereafter in later gestation. But in women who developed preeclampsia sFlt1 levels increased more up to 29 weeks and later on showed a declining trend in these women as compared to controls.

Studies of sFlt-1 have shown conflicting results. Levine et $\mathrm{al}^{8}$ found elevated levels of circulating sFlt-1 five weeks before clinical preeclampsia, but detected no association with sFlt-1 in second trimester. Two other studies by Thandani et $\mathrm{al}^{12}$ and Power et $\mathrm{al}^{12}$ failed to show any association with sFlt-1 but Hertig et al showed that high concentration of sFlt-1 late in second trimester was associated with increased risk of preeclampsia. ${ }^{13}$

Our study showed rapid fall in sFlt1 levels in post partum period in both controls and cases. Similar observations have been made by other workers ${ }^{12}$. The decrement in our study however was lesser in preeclamptic group. Possible explanation for this

slower decrease could be due to either slower excretion or higher rate of production as placenta is not the only site for production of $\mathrm{sFlt}^{14}$ significantly disturbed normal mechanism of sFlt1 clearance from the body in preeclamptic women cannot be ruled out ${ }^{13}$.

Our study also had the same limitation. We did not look for the alterations in the angiogenic markers in other obstetric conditions similar to preeclampsia, such as gestational hypertension and pregnancy induced hypertension(PIH). Since preeclampsia is a syndrome so no single test will predict preeclampsia risk, for better results combination of marker required in our study we did not look for the other angiogenic markers levels like VEGF and PLGF.

We were able to analyze samples collected prior to the onset of symptoms in all preeclamptic cases from a large 
prospective, carefully monitored cohort. Thus, we were able to minimize selection bias.

The study needs to done on a large sample before making a final statement on its significant impact reliable prediction and management of preeclampsia. It would allow earlier diagnosis of preeclampsia and closer prenatal monitoring.

Acknowledgement: We are grateful to Uttar Pradesh Council of Science and Technology (UPCST) for the financial support.

\section{Conflict of interest: Nil}

\section{Permission from IRB: Yes}

\section{References}

1. Report of the National High Blood Pressure Education Program Working Group on High Blood Pressure in Pregnancy. Am J Obstet Gynecol. Jul 2000; 183(1): S1S22.

2. Williams D. Long-term complications of pre-eclampsia. Semin Nephrol. 2011; 31(1):111-22.

3. Young BC, Levine RJ, Karumanchi SA. Pathogenesis of preeclampsia. Ann Rev Pathol 2010; 5:173-192.

4. Kendall RL, Thomas KA. Inhibition of vascular endothelial cell growth factor activity by an endogenously encoded soluble receptor. Proc Natl Acad Sci U S A.1993;90:10705 10709.

5. He Y, Smith SK, Day KA, Clark DE, Licence DR, Charnock-Jones DS. Alternative splicing of vascular endothelial growth factor (VEGF)-R1 (FLT-1) pre-mRNA is important for the regulation of VEGF activity.Mol Endocrinol. 1999;13:537-545.

6. Vuorela P, Helske S, Hornig C, Alitalo K, Weich H,Halmesma"ki E. Amniotic fluid-soluble vascular endothelial growth factor receptor-1 in preelcampsia. Obstet Gynecol 2000;95:353-7.
7. Maynard SE, Min JY, Merchan J, Lim KH, Li J, Mondal S, Libermann TA, Morgan JP, Sellke FW, Stillman IE, Epstein FH, Sukhatme VP, Karumanchi SA.. Excess placental soluble fms-like tyrosine kinase 1 (sFlt-1) may contribute to endothelial dysfunction, hypertension, and proteinuria in preeclampsia. J Clin Invest. 2003 Mar;111(5):649-58

8. Levine RJ, Maynard SE, Qian C, Lim KH, England LJ, Yu KF, Schisterman EF, Thadhani R, Sachs BP, Epstein FH, Sibai BM, Sukhatme VP, Karumanchi SA. Circulating angiogenic factors and the risk of preeclampsia. N Engl J Med. 2004 Feb 12;350(7):672-8

9. Tidwell SC, Ho HN, Chiu WH, Torry RJ, Torry DS. Low maternal serum levels of pla-centa growth factor as an antecedent of clinical preeclampsia. Am J Obstet Gynecol 2001; 184: 1267-72.

10. Krauss T, Pauer HU, Augustin HG. Prospective analysis of placenta growth factor (PIGF) concentrations in the plasma of women with normal pregnancy and pregnancies complicated by preeclampsia. Hypertens Pregnancy 2004; 23: 101-11.

11. Thadhani R, Mutter WP, Wolf M, Levine RJ, Taylor RN, Sukhatme VP, Ecker J, Karumanchi SA. First trimester placental growth factor and soluble fms-like tyrosine kinase 1 and risk for pre-eclampsia. J Clin Endocrinol Metab. 2004 Feb;89(2):770-5

12. Powers RW, Roberts JM, Cooper KM, Gallaher MJ, Frank MP, Harger GF, Ness RB. Maternal serum soluble fms-like tyrosine kinase 1 concentrations are not increased in early pregnancy and decrease more slowly postpartum in women who develop pre-eclampsia. Am $\mathbf{J}$ Obstet Gynecol 2005;193(1):185-91.

13. Hertig A, Berkane N, Lefevre G, Toumi K, Marti HP, Capeau J, Uzan S, Rondeau E. Maternal Serum sFlt1Concentration is an early and reliable predictive marker of preeclampsia. Clin Chem. 2004 Sep;50 (9):1702-3 
14. Rajakumar A, Michael HM, Rajakumar PA, Shibata E, Hubel CA, Karumanchi SA, et al. Extra-placental expression of vascular endothelial growth factor receptor1, (Flt-1) and soluble Flt-1 (sFlt-1), by peripheral blood mononuclear cells (PBMCs) in normotensive and preeclamptic pregnant women. Placenta. 2005 Aug; 26(7): $563-73$

\section{How to cite this article?}

Yadav S, Singh Y, Natu SM, Goel MM, Singh U, Tondon P. Serum Levels of Soluble Fms like Tyrosine Kinase-1(sFlt-1) in Normotensive and Preeclamptic Pregnancy. Int J Med Res Rev 2013;1(3):114-119. doi:10.17511/ijmrr.2013.i03.07 